\title{
Closed Die Hot Forging Process Analysis using Qform
}

ISSN: 2576-8840

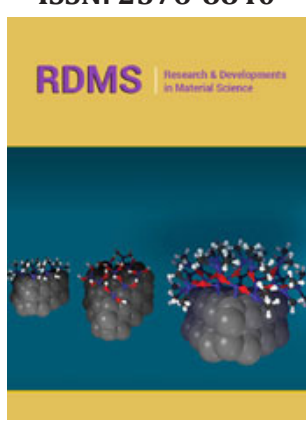

*Corresponding author: Tripathy S, Department of Mechanical Engineering, Institute of Technical Education and Research, Siksha 'O' Anusandhan (Deemed to be University), India

Submission: 侮 May 18, 2021

Published: 制June 01, 2021

Volume 15 - Issue 3

How to cite this article: Smrutiranjan Biswal, Tripathy S, Tripathy DK. Closed Die Hot Forging Process Analysis using Qform. Res Dev Material Sci. 15(3). RDMS.000861. 2021. DOI: 10.31031/RDMS.2021.15.000861

Copyright@ Tripathy S. This article is distributed under the terms of the Creative Commons Attribution 4.0 International License, which permits unrestricted use and redistribution provided that the original author and source are credited.

\author{
Smrutiranjan Biswal ${ }^{1}$, Tripathy $\mathrm{S}^{2 *}$ and Tripathy $\mathrm{DK}^{3}$ \\ 1,2Department of Mechanical Engineering, Institute of Technical Education and Research, India \\ ${ }^{3}$ Ex-Professor Emeritus, IIT Kharagpur, India
}

\begin{abstract}
Forging is widely adopted manufacturing method in automotive machine parts, aerospace components due to the good quality, high efficiency and less scrap generated by the process in comparison to other manufacturing methods. After heat treatment it gives comparatively good mechanical properties and fine grains which are advantageous for components used in high load conditions. In metal forging, to get desired shape and properties of product parameters like material selection, design parameter optimization, process parameter optimization is implemented which will lead to good microstructure. In closed die hot forging, which is one of the oldest forging processes, deformation occurs on metals having temperature more than its recrystalline temperature. Deformation occurs between two dies to shape the metal in the die cavity under an external pressure. In this paper simulation of closed die forging of an automotive component carried out using commercially available Q form software package. Analysis of material filling, temperature and stress profile done using $Q$ form. Various factors like workpiece temperature, initial die temperature, shape of the die-cavity, stress and strain-rate influence the forging process. Contact between die and billet during deformation induces stress on both die and workpiece. This stress has direct impact on metal flow, die filling and life of die. Strain rate also plays a vital role in metal flow, microstructure of the component. So, it is important to study the stress profile of the process in various stage to predict the optimize shape of the die cavity, temperature and load required for the process. Finite element simulation is the method by which the process can be carried out using a software package.
\end{abstract}

Keywords: Forging; Finite element analysis; Qform; Closed die forging

\section{Introduction}

The closed die hot forging is processed to transform a simple geometry into the desired final shape by controlling its plastic deformation. In closed die forging, the die imparts pressure on the material through the interface which results in the generation of cavity shaped component. The hot forging criteria together with closed die condition, can produce a higher degree of deformation with reasonable geometrical accuracy, making it a preferred process for mass production of parts with complex shape. The physical phenomena defining a complex closed die hot forging operation are generally difficult to express in terms of quantitative relationships. The input and output parameters, their interrelationship need to be studied along with their effect on product quality for improving the efficiency of the process. Along with this, an understanding of metal flow, its direction, the influence of the extent and rate of deformation in conjunction with the effect of temperature would be vital in controlling the process [1].

The flow stress refers to the instantaneous value of stress, under the given condition of temperature which is required for continuous deformation or flow of material. This is the most vital material variable in the metal forming analysis. For a given material, the flow stress $(\bar{\sigma})$ is a function of degree of deformation or strain $(\epsilon)$, rate of deformation or strain rate $(\dot{\epsilon})$ and temperature of deformation $(T)$ [2].

$$
\bar{\sigma}=f(\varepsilon, \dot{\epsilon}, T) \ldots \ldots(\text { Eq.1.1) }
$$

The temperature of forging the strain hardening is low; hence the rate of deformation or strain rate has a far greater effect on flow stress. The increase in strain rate, increases the values of flow stress, in most cases. FEA models can be used to fill the die and produce stress impact, causes of laps, location of high stress induced [3] Using finite element method 
simulation the residual stress can be predicted on forging processes. The comparison between experimental data and simulation data will provide a close relation between actual data and predicted data [4]. Abrasive wear and Low Cycle Fatigue (LCF) have the greatest influence on the durability of dies. Majority of researchers do not take into account the plastic strain component for estimation of the fatigue durability of the dies and use only elastic component of the Manson-Coffin's law or model of Basquin that is based on the analysis of the stress cycle. This has been implemented for LCF simulation of the die in hot forging in FE program QForm by introducing a special subroutine. The comparison of results of the die fatigue failure simulation has shown good correspondence with practice [5].

Material selection is an important factor to reduce the energy consumption and meet pollution reduction requirements. It is also important to design the die and cost of the product. The following alloys and its composites are usually used in metal forging process. Al- Based alloys, Carbon Steels, Mg, Ni and Ti based alloys. Due to advantages like high specific strength, low density, good corrosion resistance, aluminum alloy has become the most widely used lightweight structural material in aviation, aerospace, automotive, weapons, machinery manufacturing, ships, and other fields [6]. Researchers have focused much on influences of forging parameters considering mechanical and thermal parameters of aluminium alloys.

Konstantinov et al. [7] used finite element method for isothermal die forging model of aluminium 5053 alloy having deformation rate of $0.3 \mathrm{~mm} / \mathrm{s}$, billet-heating temperature $450{ }^{\circ} \mathrm{C}$, and the temperature of a die $400{ }^{\circ} \mathrm{C}$ which reduces the number of passes from three to one and increases the material utilization rate from 0.44 to 0.77 . Peng-wei et al. [8] investigated deformation behaviour of AA2014 forging aluminium alloy temperatures of 350$480{ }^{\circ} \mathrm{C}$ and strain rates of $0.001-1 \mathrm{~s}-1$ on a Gleeble- 3180 simulator. Process map have been constructed with strains $0.1,0.3,0.5$ \& 0.7. The optimum hot working parameters for the AA2014 forging aluminum alloy were determined to be $370-420{ }^{\circ} \mathrm{C}$ and 0.008 $0.08 \mathrm{~s}-1$ with uniform microstructure. Kim et al. [9] used the finite element method to analyze the forging process of 6061 aluminum alloy wheels and studied the influence of forging speed on the metal filling. They found that slow forging speed highly decreases the surface temperature and results in severe flow ability reduction. Recent study shows aluminium composites used in industries for forging achieves superior mechanical properties in comparison to other metal alloys. Researchers found that yield stress, ductility, tensile strength, hardening behavior, strain hardening and tribological properties were improved. Grain flow and alignment of microstructure was also uniform which is necessary for the strength of the composites.

The environmental polices are now focusing on weight reduction of automobile parts to reduce the fuel consumption causing pollution. Magnesium alloys are found advantageous and have good weight to strength ratio, light weight, good heat dissipation properties in comparison to other alloys. Recent automobile trends are using magnesium alloys to make low thermal exposed components like brackets, covers, automobile body parts [10]. Researchers have focused on improvement of strength, ductility, toughness etc.

Jing et al. [11] investigated effect of forging temperature on mechanical properties and microstructure of AZ31 magnesium alloy ring. The grain structure significantly refined, and grain growth was observed along with increase of forging temperature. Ductility is less affected by grain size for magnesium AZ31 ring. Shi quan et al. [12] investigated the deformation behaviour of AZ80 magnesium alloy and determined the optimum deformation condition as 623$683 \mathrm{~K}$ and $0.0001-0.1 \mathrm{~s}-1$.

Facai [13] investigated hot deformation behaviour of AISI 420 martenistic stainless steel in a temperature range 1123-1423K and strain rate of $0.01-10 \mathrm{~s}-1$ determined that the optimum hot working condition for forging of AISI 420 martensitic stainless steel is 1280$1360 \mathrm{~K}$ and strain rate range is $0.01-0.05 \mathrm{~s}-1$.

Aneta Łukaszek-Sołek [14] studied the hot deformation behaviour of 4340 steel in a temperature range of $800-1100{ }^{\circ} \mathrm{C}$ and strain rate of $0.01-100 \mathrm{~s}-1$ determined that is significantly more dependent upon thermal changes than the strain rate changes. Steel is used to manufacture automobile and aerospace components by forging process due to reduced weight and cost parameters. Steel is used in automobile industry for manufacturing of engine parts like crank shaft, connecting rod, pistons body parts like wheel hub for its properties like high density, yield stress, specific strength at low cost.

Titanium alloys are widely used in aerospace and automobile industriesfor its high strength, low density, good corrosion resistance but they are much more difficult to process because of their high flow stress and poor formability. Microstructure has significant effect on mechanical properties of Ti alloy. Xuemei et al [15] analysed the effect of forging temperature on mechanical properties of Ti alloy and concluded that fracture toughness improves with the elevation of forging temperature he BT25 alloy has quite high tensile strength at all studied deformation temperatures. Ultimate strength and yield strength get the maximum values of $1217 \mathrm{MPa}$ and $1133 \mathrm{MPa}$ respectively at $880{ }^{\circ} \mathrm{C}$ due to the homogeneous microstructure and interface strengthening.

\section{FE analysis technique used in forging simulation}

Simulation is the process of conducting virtual computerbased experiments, found on mathematical and logical modeling techniques. Design by simulation is a systematic approach where the objective is to perform virtual iterative trials to understand the effect of parameters on the output and the overall behavior of the system. In forging the simulation technique can be used both for process analysis and die design. The purposes of process modeling through simulation are to gain a comprehensive insight into the process to understand different mechanisms and phenomena involved. The study can be performed in isolation, so that actual setup is not disturbed. It reduces effort on expensive trials by 
reducing the overall development time. Testing the effectiveness of new concepts before actual implementation reduces effort on analytic requirements. To find out the results in easily demonstrable models, which can be further scaled to advanced analysis, such as die wear, die life estimation etc. [15-17].
In the simulation process component drawing is prepared as per specification using CAD software and commercially available solid works software was used to prepare component drawing as shown in Figure 1.

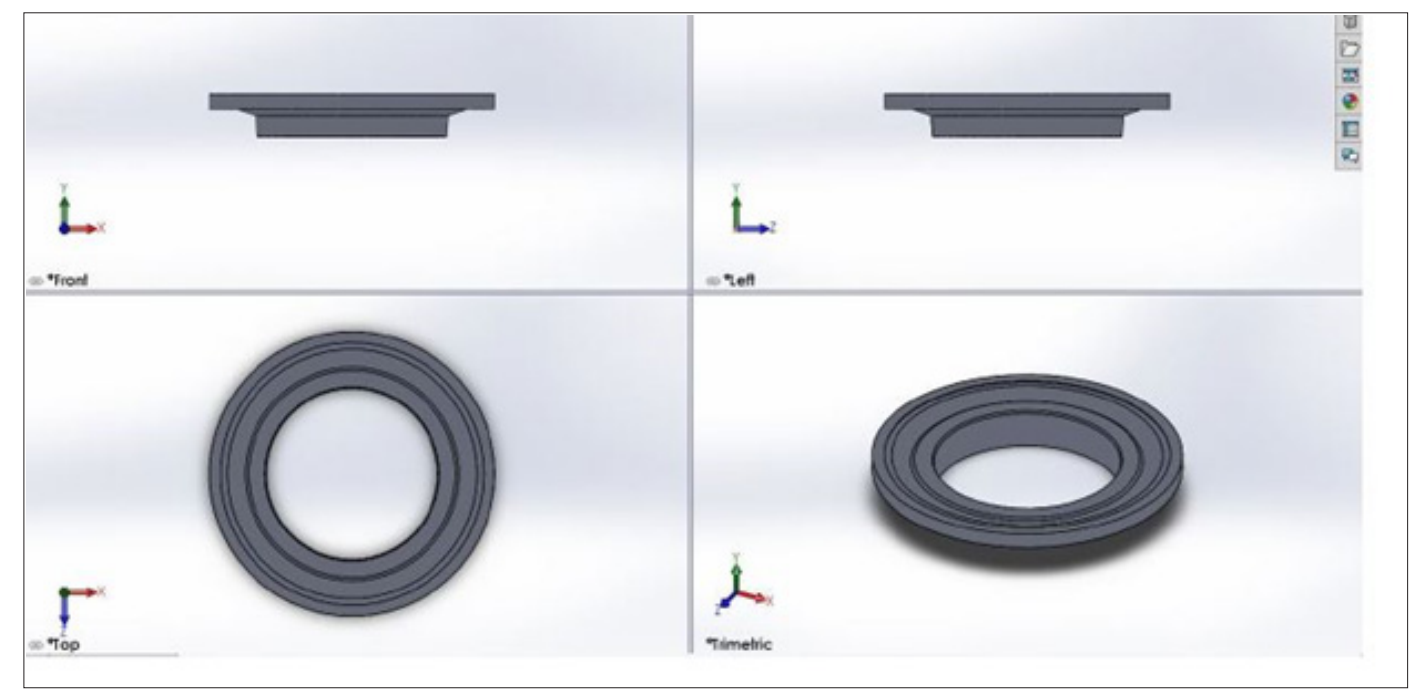

Figure 1: Component drawing of automotive part Hub.

The component drawing shown in Figure 2 was converted into die drawing following Indian standard IS 3469 for tolerances applicable to closed die steel forging. As per process requirement, separate dies were designed for upsetting, blocking, and finishing stages. The visual representations during process are given in Figure 3.

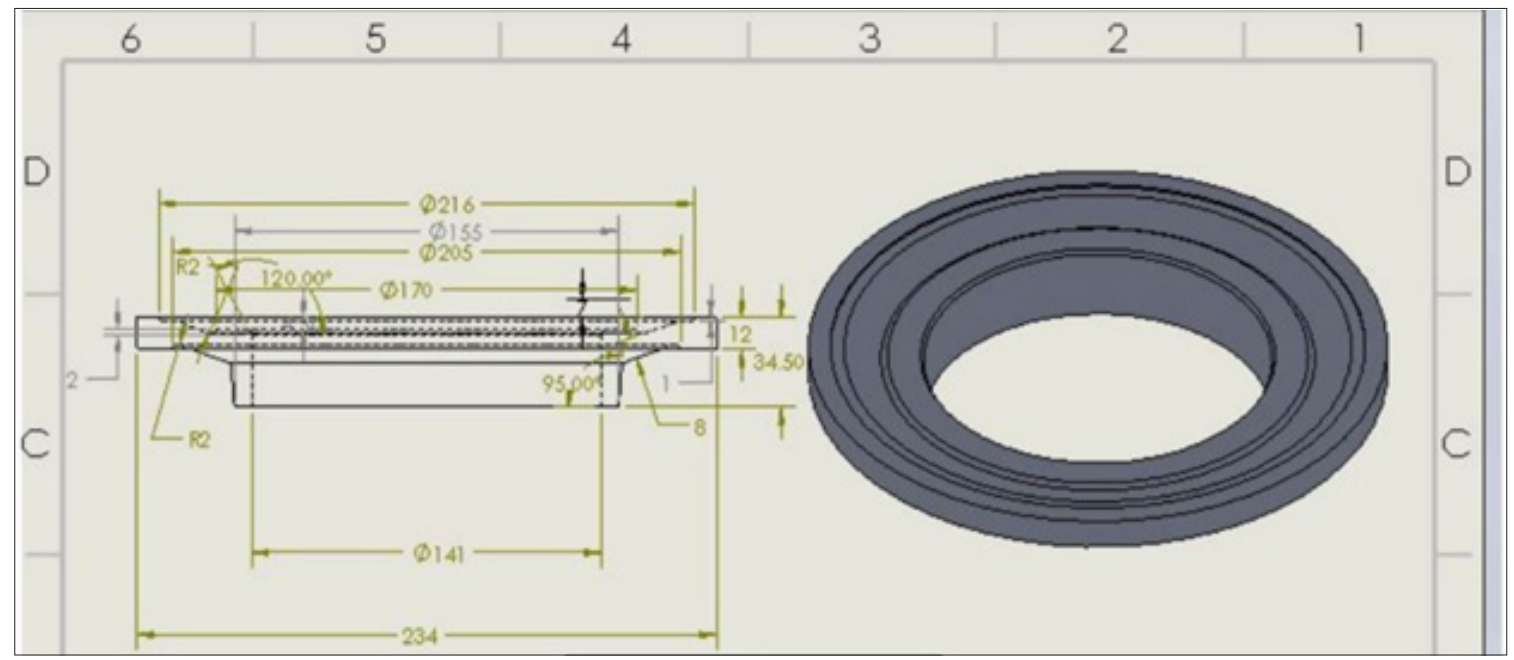

Figure 2: Component drawing for automotive part hub.

\section{Analysis using QForm}

Temperature profile of various stages in closed die hot forging process was analysed considering parameters like initial workpiece temperature, tool material, initial tool temperature, lubricant, stop conditions etc. This will help to predict the temperature generated during the process. This temperature has direct impact on metal flow and microstructure. The graph between load and time has also been shown to predict the required load and its impact on material filling at various stages.

The details of load and temperature profile for different stages of upsetting, blocker and finisher is shown in Tables 1-3. The temperature profile generated is shown in Figures 4, 6 \& 8 for upsetting, blocker and finisher. The load time and work time diagrams are also shown in Figures 5,7 \& 9. 


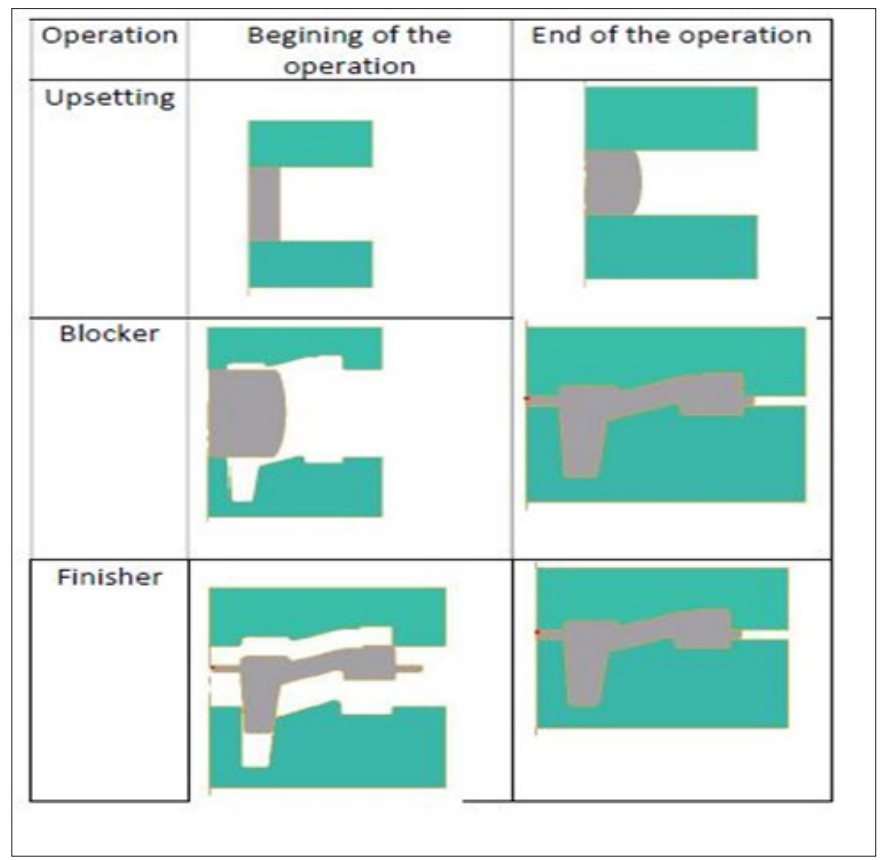

Figure 3: Visual representations of process during different stages.

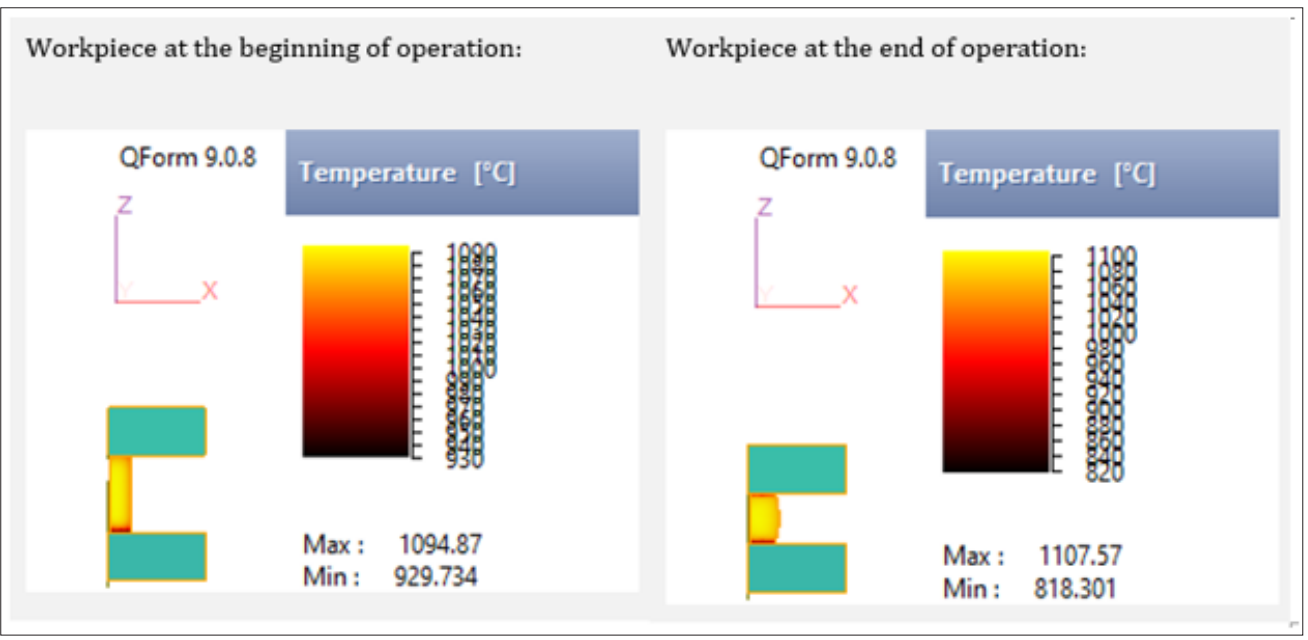

Figure 4: Temperature profile during upsetting

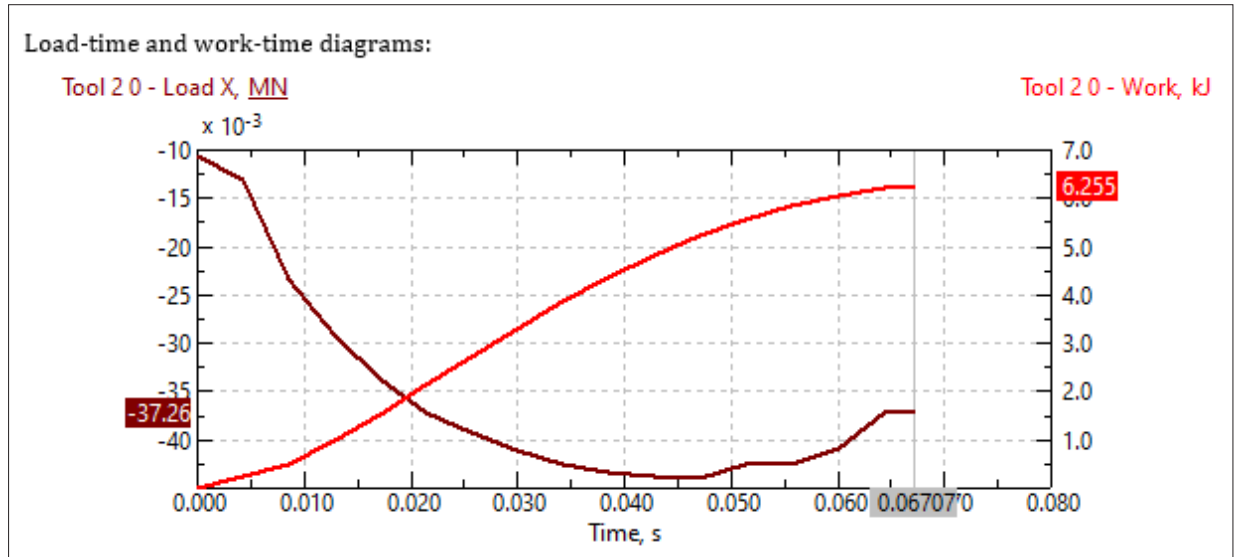

Figure 5: Load-time and work-time diagram for upsetting. 


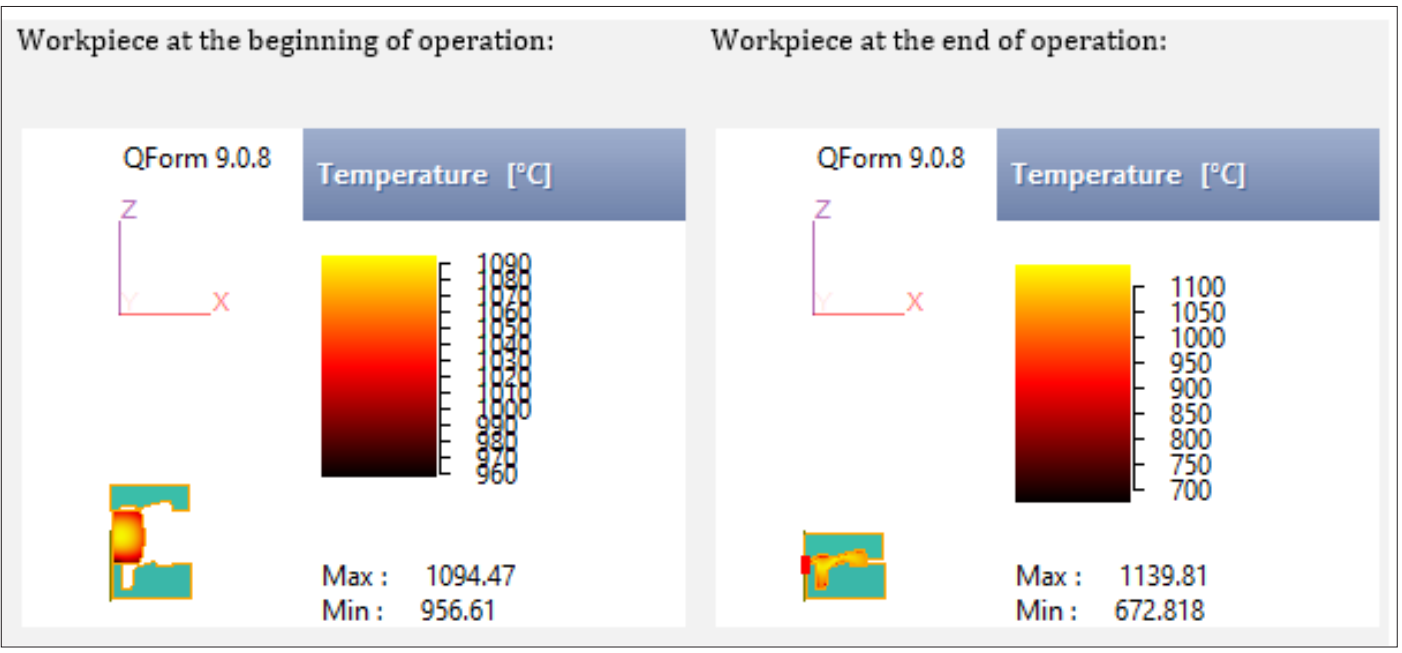

Figure 6: Temperature profile during blocker.

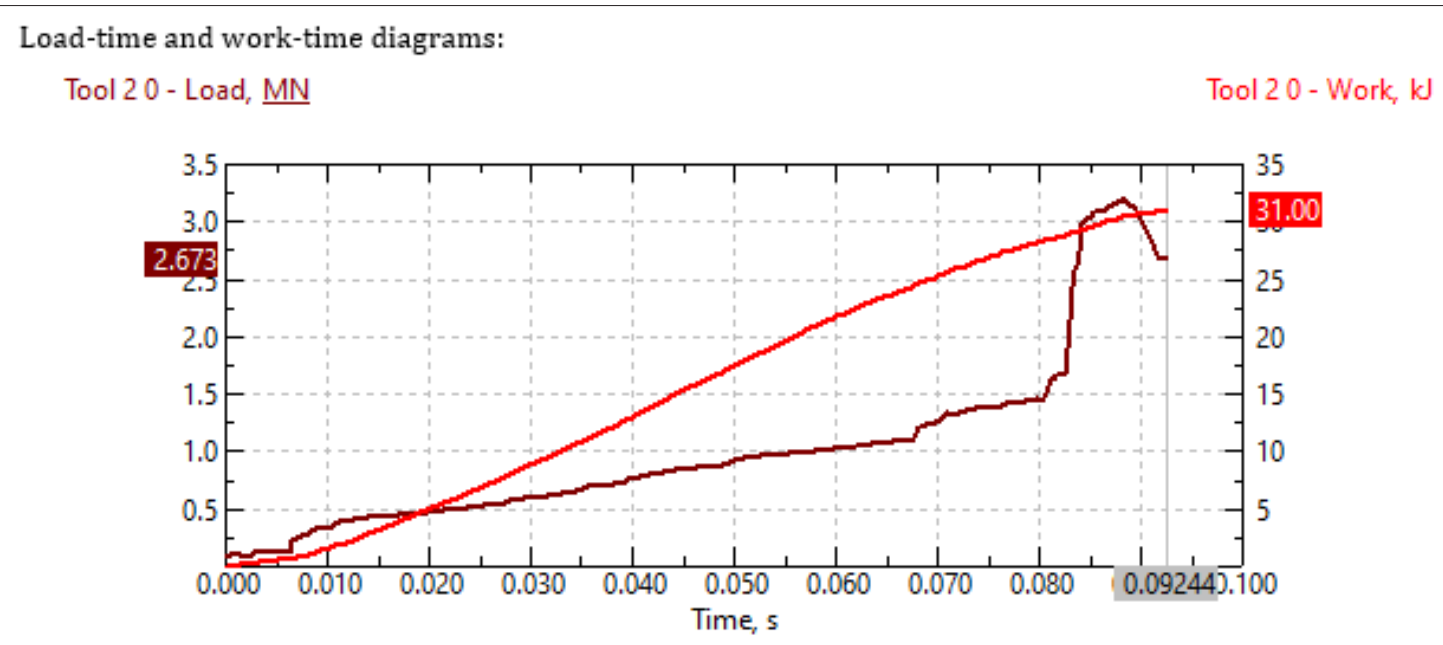

Figure 7: Load-time and work-time diagram for blocker.

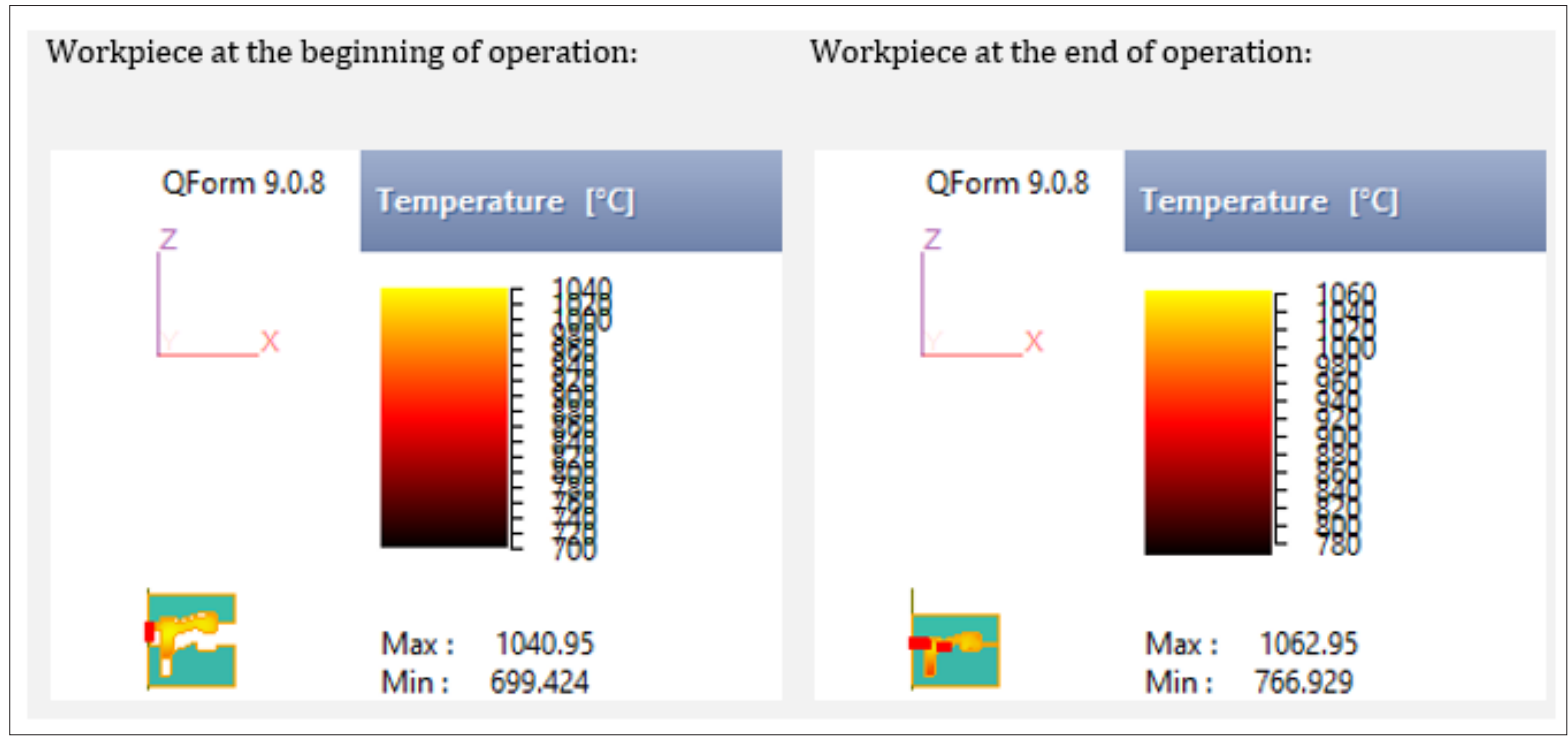

Figure 8: Temperature profile during finisher. 


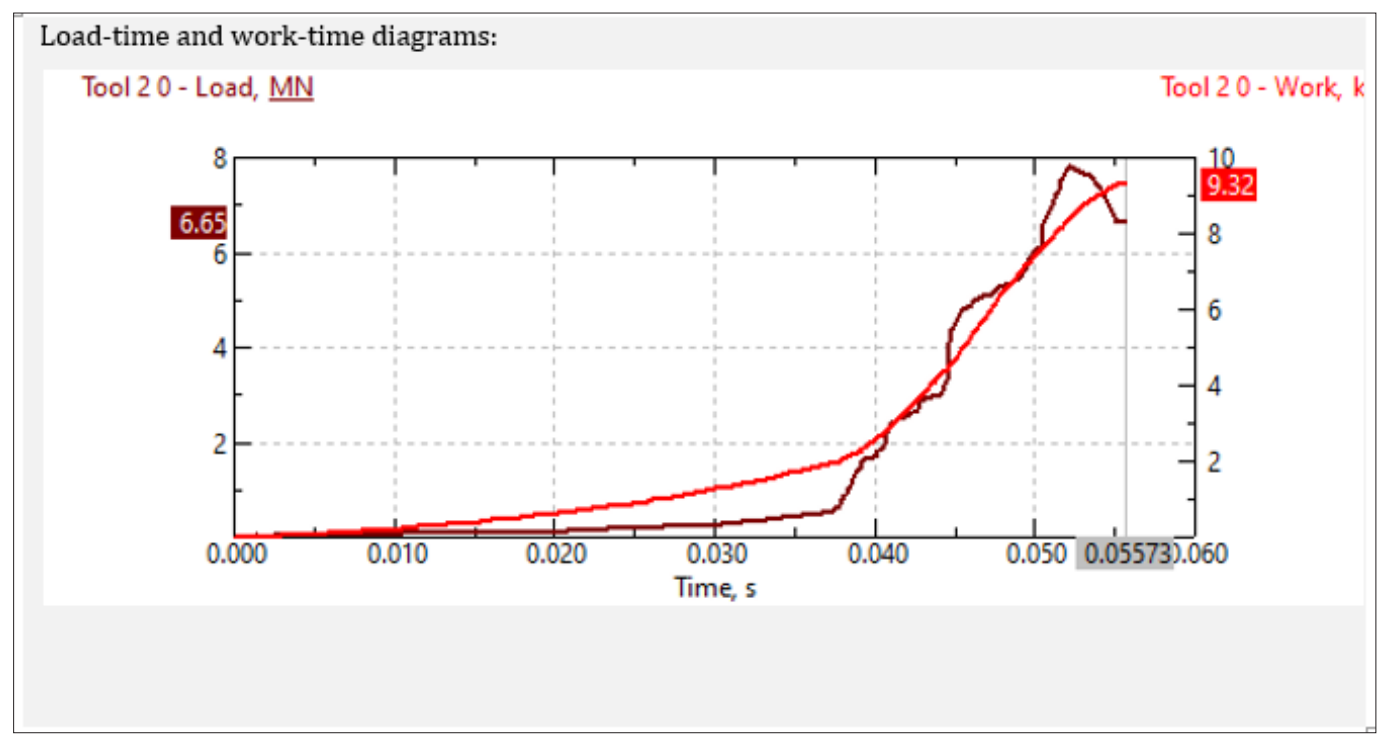

Figure 9: Load-time and work-time diagram for finisher.

Table 1: Load and temperature profile for upsetting

\begin{tabular}{|c|c|}
\hline \multicolumn{2}{|c|}{ Operation Name: Upsetting [1] } \\
\hline Workpiece material: & $41 \mathrm{Cr} 4(1-7035)$ \\
\hline Initial workpiece temperature: & $1100^{\circ} \mathrm{C}$ \\
\hline Tool material: & L6 HRC42 \\
\hline Initial tool temperature: & $200^{\circ} \mathrm{C}$ \\
\hline Equipment of top tool: & $25 \mathrm{MN}$ \\
\hline Equipment of bottom tool: & + OZ \\
\hline Lubricant: & Graphite + water \\
\hline Stop conditions: & Condition 1 Distance \\
\hline Cooling in air: & $5 \mathrm{~s}$ \\
\hline Cooling on tool: & $2 \mathrm{~s}$ \\
\hline Solving time: & $5 \mathrm{~s}$ \\
\hline
\end{tabular}

Table 2: Load and temperature profile for blocker.

\begin{tabular}{|c|c|}
\hline \multicolumn{2}{|c|}{ Operation Name: Blocker [2] } \\
\hline Initial workpiece temperature: & Inherited from previous operation ${ }^{\circ} \mathrm{C}$ \\
\hline Tool material: & L6 HRC42 \\
\hline Initial tool temperature: & $200^{\circ} \mathrm{C}$ \\
\hline Equipment of top tool: & Mechanical press \\
\hline Equipment of bottom tool: & Fixed \\
\hline Lubricant: & Graphite + water \\
\hline Stop conditions: & $5 \mathrm{~s}$ \\
\hline Cooling in air: & $2 \mathrm{~s}$ \\
\hline Cooling on tool: & $33 \mathrm{~s}$ \\
\hline Solving time: & \\
\hline
\end{tabular}

Table 3: Load and temperature profile for finisher.

\begin{tabular}{|c|c|}
\hline \multicolumn{2}{|c|}{ Operation Name: Finisher [3] } \\
\hline Initial workpiece temperature: & Inherited from previous operation ${ }^{\circ} \mathrm{C}$ \\
\hline Tool material: & L6 HRC42 \\
\hline
\end{tabular}




\begin{tabular}{|c|c|}
\hline Initial tool temperature: & $200{ }^{\circ} \mathrm{C}$ \\
\hline Equipment of top tool: & Mechanical press \\
\hline Equipment of bottom tool: & Fixed \\
\hline Lubricant: & Graphite + water \\
\hline Stop conditions: & Condition 1 Distance \\
\hline Cooling in air: & $5 \mathrm{~s}$ \\
\hline Cooling on tool: & $2 \mathrm{~s}$ \\
\hline Solving time: & $27 \mathrm{~s}$ \\
\hline
\end{tabular}

Strain rate has a major influence in forging process. So, the stress profile is required to analysis stress induced at various stages as shown in Figure 10. By this maximum and minimum stress induced on workpiece and die can be analysed. Considering this modification in die design can be carried out to avoid application of maximum load. The stress profile of finisher stage is given in Figure 10.

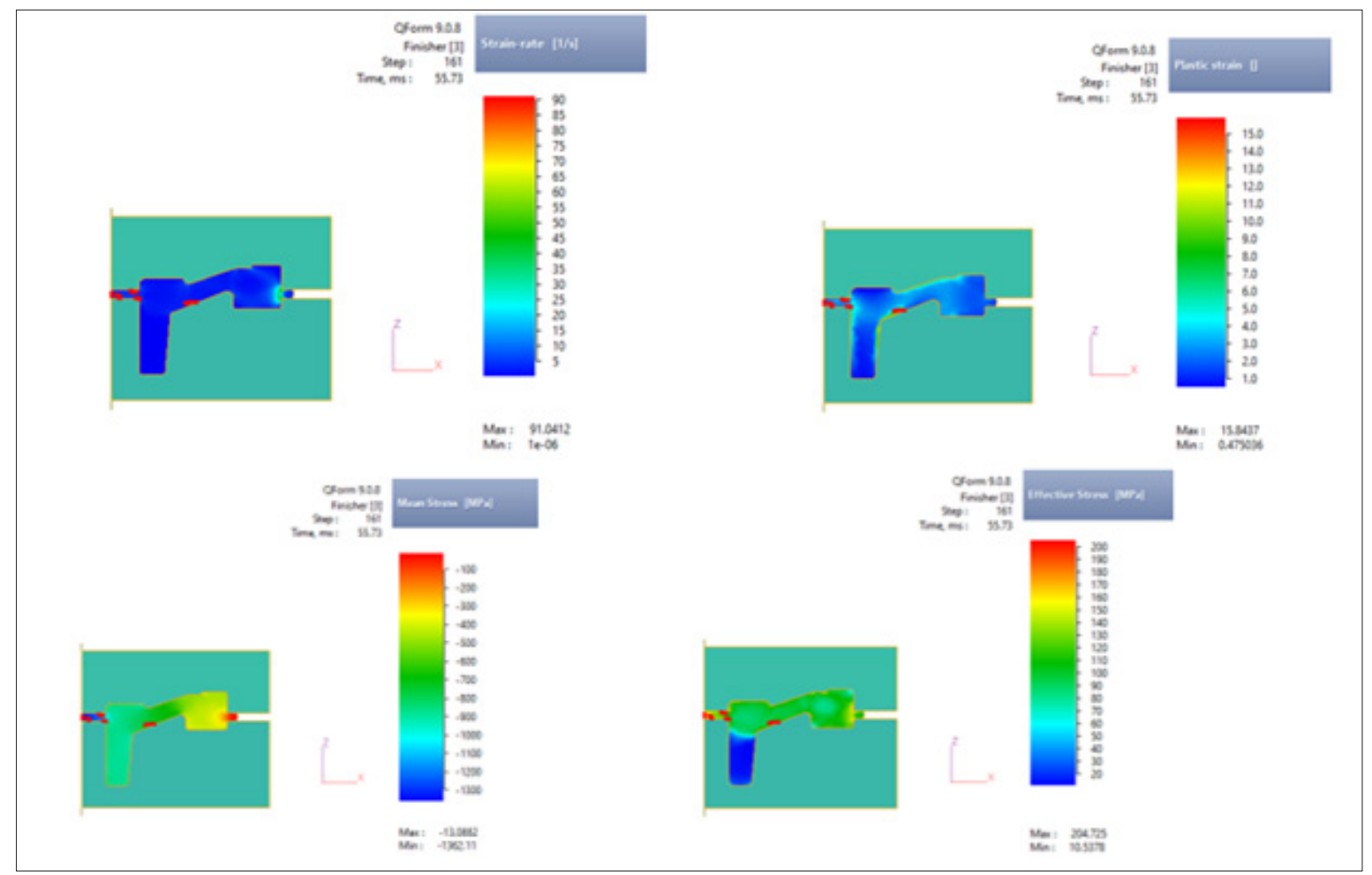

Figure 10: Stress profile of finisher stage.

\section{Conclusion}

In this paper simulation for closed die hot forging process of an automotive component has been carried out using $Q$ form software package. The conclusion can be drawn as:

a) Using simulation methods, the whole process can be studied to get optimized parameters influencing the process.

b) Material wastage can be reduced due to pre-defined die design.

c) Material flow \& microstructure can be studied to improve quality of product.

d) These above have direct impact on manufacturing cost per unit which can give economical advantages to manufacturers.

\section{References}

1. Altan T, Ngaile G, Shen G (2004) Cold and hot forging: fundamentals and applications. ASM international, USA.

2. Dieter GE, Kuhn HA, Semiatin SL (2003) Handbook of workability and process design. ASM international, USA.

3. Hawryluk M, Jakubik J (2016) Analysis of forging defects for selected industrial die forging processes. Engineering Failure Analysis 59: 396409.

4. Liu L, Sun J, Chen W, Sun P (2017) Study on the machining distortion of aluminum alloy parts induced by forging residual stresses. Proceedings of the Institution of Mechanical Engineers, Part B: Journal of Engineering Manufacture 231(4): 618-627.

5. Vlasov A, Biba N, Stebunov S (2016) Elastic-plastic thermomechanical fatigue analysis of forging dies. In Key Engineering Materials 716: 667676. 
6. Hirsch J (2014) Recent development in aluminium for automotive applications. Transactions of Nonferrous Metals Society of China 24(7): 1995-2002.

7. Konstantinov IL, Sidelnikov SB, Voroshilov DS, Belyaev SV, Gorokhov YV, et al. (2020) Use of computer simulation for modernization technology of aluminum alloys hot die forging. The International Journal of Advanced Manufacturing Technology, 1-7.

8. Li PW, Li HZ, Huang LAN, Liang XP, Zhu ZX (2017) Characterization of hot deformation behavior of AA2014 forging aluminum alloy using processing map. Transactions of Nonferrous Metals Society of China 27(8): 1677-1688.

9. Kim YH, Ryou TK, Choi HJ (2002) An analysis of the forging processes for 6061 aluminum-alloy wheels. Journal of Materials Processing Technology123(2): 270-276.

10. Blawert C, Hort N, Kainer KU (2004) Automotive applications of magnesium and its alloys. Trans Indian Inst Met 57: 391-408.

11. Zhang J, Huang H, Yang C (2017) Effects of hot ring forging on microstructure, texture and mechanical properties of AZ31 magnesium alloy. Materials Science and Engineering: A 679: 20-27.
12. Huang S, Lu M, Luo S, He H, Yi Y (2019) Hot deformation characteristics and processing map analysis of pre-forged AZ80 magnesium alloy. Metals and Materials International.

13. Ren F, Chen F, Chen J, Tang X (2018) Hot deformation behavior and processing maps of AISI 420 martensitic stainless steel. Journal of Manufacturing Processes 31: 640-649.

14. Łukaszek-Sołek A, KrawczykJ, Śleboda T, Grelowski J (2019) Optimization of the hot forging parameters for 4340 steel by processing maps. Journal of Materials Research and Technology 8(3): 3281-3290.

15. Lisiecki Ł, Skubisz P, Kanevskiy S, Mordvintsev P Predicting fracture in closed-die forgings. parameters 2: 4.

16. Samal C (2014) Study of process parameters towards improving efficiency of closed die hot forging process.

17. Biba N, Stebounov S, Lishiny A (2001) Cost effective implementation of forging simulation. Journal of Materials Processing Technology 113(13): 34-39. 